\title{
Paradoxo no sistema: o mundo de porteiras abertas, mas fronteiras fixadas no Facebook
}

\author{
Paradox in the system: the world with open doors but fixed \\ borders on Facebook
}

\author{
Êmili Adami Rossetti, Universidade do Porto, Brasil. \\ Av. Sen. Salgado Filho, 3000 - Candelária, Natal - RN, 59064-741, Brasil \\ emilix10@gmail.com | Orcid: https://orcid.org/0000-0002-1359-3998
}

DOI: http://dx.doi.org/10.12795/Ambitos.2019.i45.08

\section{Resumo}

Esta investigação une os estudos em comunicação social acerca das tecnologias digitais de informação e comunicação, com foco principalmente nas interações em mídias digitais, com pensamentos filosóficos sobre a construção do conhecimento. Aqui acessamos o paradigma da complexidade e a fenomenologia da percepção, representados respectivamente pelo pensamento de Edgar Morin e Maurice MerleauPonty, para apontar que o conhecimento é um construto do homem conforme sua experiência. É, portanto, contextual, histórico e perceptual, não o contrário, como sugere a ciência moderna em seu intuito de extrair a verdade das coisas. Tendo como base essa discussão, voltamo-nos ao Facebook, maior mídia social digital da atualidade, para vê-lo como viabilizador de intercâmbio de informações e como meio que possibilita a transcendência das limitações de espaço e de tempo em que se encontram os corpos dos participantes das interações comunicacionais. Partimos da ideia de que essa plataforma pode ser vista como uma possibilitadora de expansão das vivências do sujeito no espaço e no tempo, levando-o a pensar novas realidades, que são integradas 
à construção do conhecimento. Mas, paradoxalmente, as informações são organizadas e o acesso a elas é limitado pela corporação Facebook, que, além disso, provém dados sobre seus usuários para manipulação de mensagens por parte de anunciantes, o que vai balizar o conhecimento de mundo construído e limitar a liberdade do usuário.

\begin{abstract}
The research links studies in social communication about digital information and communication technologies, focusing mainly on interactions in digital media, with philosophical thoughts on the construction of knowledge. Here we access the paradigm of complexity and the phenomenology of perception, represented respectively by the thoughts of Edgar Morin and Maurice Merleau-Ponty, to point out that knowledge is a construct of men according to their experiences. It is, therefore, contextual, historical and perceptual, not the opposite, as modern science suggests in its attempt to extract truth from the objects. Based on this discussion, we turn to Facebook, the largest digital social media today, to see it as an enabler of information exchange and as a means of transcending the limitations of space and time in which the bodies of the participants in communicational interactions are. We start from the idea that this platform can be seen as a facilitator to expand the experiences of the subjects in space and time, leading them to think about new realities that are then integrated into the construction of knowledge. However, paradoxically, the information is organized and the access to it is limited by Facebook Corporation, which, in addition, provides data on its users to manipulate messages by advertisers, which will define the limits of knowledge of the world and limit the freedom of its users.
\end{abstract}

Palavras-chave: complexidade, fenomenologia da percepção, liberdade, Facebook.

Key words: complexity, phenomenology of perception, liberty, Facebook.

\title{
1. INTRODUÇÃO: A COMPLEXIDADE DO MUNDO E A EXPERIÊNCIA COMO CONHECIMENTO
}

Para a ciência moderna, imbuída do positivismo que separa o sujeito que observa do objeto que é observado, sensação e percepção são distintas e se relacionam no esquema estímulo-resposta: a percepção é apreendida de um objeto pela consciência (o sujeito) utilizando-se da sensação como instrumento. No entanto, Merleau-Ponty constrói um novo conceito sobre a percepção que inclui os limites do corpo e a vivência do sujeito, historicidade, relações sociais, tensões e contradições, amor, objetos culturais e movimento. A percepção é uma experiência corporal e é mais subjetiva que objetiva. Com sua ideia de campo fenomenal, leva em consideração o eu, o outro e as coisas para a interpretação do mundo a partir da história e da cultura. O ser e o mundo são indissociáveis. 
Dessa forma, a percepção não é o conhecimento exaustivo e total do objeto, mas uma interpretação sempre provisória e incompleta (...). Sob o sujeito encarnado, correlacionamos o corpo, o tempo, o outro, a afetividade, o mundo da cultura e das relações sociais. (Nóbrega, 2008, p. 141).

A ciência, assim, não pode conhecer a realidade do mundo observando uma relação de causalidades, e um sujeito não é determinado física ou psicologicamente pelas causalidades que o cruzam, ele não é um "objeto da biologia, da psicologia e da sociologia" (Merleau-Ponty, 1999, p. 3):

Tudo aquilo que sei do mundo, mesmo por ciência, eu o sei a partir de uma visão minha ou de uma experiência do mundo sem a qual os símbolos da ciência não poderiam dizer nada. Todo o universo da ciência é construído sobre o mundo vivido, e se queremos pensar a própria ciência com rigor, apreciar exatamente seu sentido e seu alcance, precisamos primeiramente despertar essa experiência do mundo da qual ela é a expressão segunda. A ciência não tem e não terá jamais o mesmo sentido de ser que o mundo percebido, pela simples razão de que ela é uma determinação ou uma explicação dele. Eu sou não um "ser vivo" ou mesmo um "homem" ou mesmo "uma consciência", com todos os caracteres que a zoologia, a anatomia social ou a psicologia indutiva reconhecem a esses produtos da natureza ou da história - eu sou a fonte absoluta. (Merleau-Ponty, 1999, p. 3)

O pensador defende que o mundo não está disponível em torno do sujeito sem que este seja parte formadora desse mundo (Merleau-Ponty, 1999), ou seja, o mundo é, ao mesmo tempo, campo da experiência que origina todos nós e cada um, e é criatura dos sujeitos no próprio mundo. Assim, a sensação não está dissociada do campo em que se encontra e o corpo não é um transmissor de mensagens puras sobre um mundo exterior em si: "O acontecimento elementar já está revestido de um sentido" (MerleauPonty, 1999, p. 31).

Aqui pode-se traçar um paralelo com as ideias de Edgar Morin e o paradigma da complexidade, para o qual os estímulos captados pelos membros de sentido do corpo são transformados num código, que é interpretado pelo cérebro e transformado em percepção ou representação. "O conhecimento não é senão uma tradução, uma reconstrução. Não conhecemos a essência das coisas exteriores. Sabemos das coisas objetivas, que podemos confirmar, mas não há conhecimento sem integração do conhecido" (Morin, 1997, p. 19).

Também o paradigma da complexidade admite que um problema não está isolado, mas é parte de um sistema e este, por sua vez, não tem sua inteligibilidade em si mesmo, ela "deve ser encontrada, não apenas no próprio sistema, mas também na sua relação com o meio ambiente, e que essa relação não é uma simples dependência, ela é 
constitutiva do sistema" (Morin, 2011, p. 22). Para Morin, o saber tem como centro uma unidade complexa, que não pode ser traduzida pela soma das partes que a constituem.

Assim como Merleau-Ponty (1999) defende que o campo sensorial - o contexto em que se encontra o objeto observado - é afetado por uma organização do próprio observador e foge da possibilidade de ser analisado por instrumentos definidos pela ciência moderna, Morin (2011) diz que é necessário que se tenha em mente que as coisas vivas não são "entidades closes", "sistemas organizando seu fechamento (isto é, sua autonomia) na e pela abertura" (Morin, 2011, p. 20. Grifo do autor). O mundo abre-se ao infinito e, nas palavras dele: "se o sujeito reflete o mundo, isso pode também significar que o mundo reflete o sujeito" (p. 42).

Para Morin (2011), não nos tornamos autônomos antes de aprendermos uma linguagem, uma cultura, saberes, que devem ser variados para que possamos exercer a escolha daquilo que seremos, de forma que a autonomia se alimenta de dependência desses fatores. Também a biologia, nossos genes, ditam como vivemos e, portanto, somos também dependentes deles. Para Merleau-Ponty (1999), somente podemos sentir após aprendermos - com a história, as tradições, a vivência do corpo - o que é cada uma das sensações.

Se o conhecimento se faz dentro de um contexto, um campo fenomenal, e se a ciência deve considerar essa dependência na análise dos objetos, então o estudo do homem não pode deixar de considerar sua interação com outros sujeitos nem as informações que tem do mundo. Os meios que utilizam para que interajam e a linguagem aplicada também não podem ser ignorados.

\section{A INTERNET COMO EXTENSÃO DO CORPO E CONTEXTO DO CONHECIMENTO}

A avidez humana por saber está na história mais longínqua da humanidade, bem como a crescente busca por meios de cada vez mais alargar fronteiras e poder conhecer outros territórios, indo além do espaço que o corpo pode alcançar por si mesmo. A criação da escrita é uma prova de que o homem, desde o início dos tempos, era desejoso da possibilidade de que outros conhecessem sua história através do tempo, que seu saber, sua forma de perceber o entorno, ficasse registrado e não se perdesse na cultura oral. Com a escrita o homem consegue vencer o tempo e os espaço. Fang (1997) enumera quatro revoluções na comunicação: 1) a união da escrita fonética grega com o papiro egípcio: "a mente humana nunca mais estaria restrita aos limites da memória. O conhecimento torna-se sem fronteiras" (p. xvii); 2) a imprensa, que "se prestou a massivas alterações políticas, religiosas, econômicas, educacionais e pessoais" (p. xvii); 3 ) a possibilidade de ter veículos de comunicação de massa dentro 
das casas, que "foram transformadas em locais centrais para a recepção de informação e entretenimento graças ao telefone, à radiodifusão, às gravações, melhorias na tecnologia de impressão e serviço de correio barato e universal" (p. xvii); 4) e a Information Highway (Fang, 1997), "construída da convergência entre computador, radiodifusão, satélites e tecnologias visuais. A comunicação está eliminando o transporte para o trabalho, os estudos e a diversão" (p. xvii). A possibilidade de comunicação ao longo do tempo se altera do modelo de um para um ou de um para todos - neste último caso, com apenas poucos indivíduos tendo acesso à posição de comunicador - para uma comunicação de muitos para muitos: basta ter acesso à internet e uma conta de e-mail ou perfil em rede social para que se possa receber informação de muitos e enviá-las igualmente a muitos; entre os informantes e os receptores podem estar amigos, conhecidos ou até mesmo pessoas e instituições desconhecidas.

Em face dessas modificações nos veículos de comunicação e na forma como os utilizamos, e do que foi dissertado acima a respeito da construção do conhecimento, é pertinente evocar a ideia de McLuhan de que "o meio é a mensagem":

Numa cultura como a nossa, há muito acostumada a dividir e estilhaçar todas as coisas como meio de controlá-las, não deixa, às vezes, de ser um tanto chocante lembrar que, para efeitos práticos e operacionais, o meio é a mensagem. Isto apenas significa que as conseqüências sociais e pessoais de qualquer meio - ou seja, de qualquer uma das extensões de nós mesmos - constituem o resultado do novo estalão introduzido em nossas vidas por uma nova tecnologia ou extensão de nós mesmos. (McLuhan, 1969, p. 21)

Para o pensador, os meios, ou veículos de comunicação, são extensões do corpo: permitem que sejam possíveis experiências em outro tempo e espaço que não aquele em que se encontra o usuário do canal. Partimos da comunicação entre pessoas - e até mesmo instituições - por mensagens enviadas por pombos-correios, passando para o sistema de correios e o telégrafo até chegar à instantaneidade dos e-mails e redes sociais virtuais. Há hoje a possibilidade de comunicação entre pessoas que não compartilham o mesmo espaço físico, momento e fuso horário para a aquisição de informações que atravessam o espaço virtual: a internet "é ao mesmo tempo uma possibilidade mundial de transmissão, um mecanismo para informação, disseminação e meio para colaboração e interação entre indivíduos e seus computadores sem limitação de fronteiras" (Leiner, et al., 2009, p. 22). Desde sua concepção, foi pensada como uma espécie de ambiente digital no qual a comunicação dar-se-ia para o enriquecimento do conteúdo informacional dos usuários de forma que poderia mudar a forma de o sujeito conhecer o mundo e construir o conhecimento, aos moldes do que nos mostram os autores mencionados: os meios se transformam, o homem se transforma. 
Quando em 1962 o psicólogo e cientista da computação C. R. Licklider pensou sua "Galatic Network" (Leiner, et al., 2009), deu início ao projeto Advanced Research Projects Agency Network - ARPANET: uma rede de computadores interligados para a troca de informações de investigações científicas. De início, o projeto estava sob a tutela do exército americano, mas, com os avanços nas pesquisas para a interligação de máquinas (incluindo, em 1972, a introdução do e-mail), a ARPANET cresce, sai do contexto militar em que foi criada e vira a Internet (Leiner, et al., 2009; Castells, 2004), que passa a ser comercializada para uso privado no início dos anos 90 . O e-mail, a partir de então, decola para ser, por mais de uma década, a maior rede de comunicação entre usuários e anuncia o tipo de atividade que se tem hoje na World Wide Web - WWW (Leiner, et al., 2009).

O mundo ligado em rede passa a ser uma realidade e as fronteiras se alargam. "A propagação da produção midiática, emanada de uma multiplicidade de pensamentos independentes, levou a aumentos do que o pós-modernismo identifica como descentralização e fragmentação, com uma dilatação de expressões de pontos de vista, quadros de referência, experiências e histórias" (Fang, 1997, p. xviii). Novas formas de interação social tornam-se possíveis a partir da formação de comunidades virtuais que dissociam as interações da localidade: "novos e selectivos modelos de relações sociais substituem formas de interação humana limitadas anteriormente" (Castells, 2004, p. 145).

Aliando esse pensamento aos de Merleau-Ponty e da complexidade, inexoravelmente temos que o uso da internet é construtor de contexto e de conceitos que são resgatados para transformar sensações e novas informações em conhecimento do mundo: a vivência do corpo, que não se destaca dos sentidos produzidos pela própria atividade de uso da máquina e pelos estímulos estéticos, além dos sentidos emitidos pelas mensagens a que se tem acesso, incluindo informações sobre outros contextos, são conseguidos na instantaneidade do agora, ainda que percorram o planeta e que sequer sejam emitidas na língua do receptor (os navegadores de internet já possuem ferramentas que, num clique, traduzem webpages e mensagens).

E-mails e redes sociais virtuais unem pessoas de todo o globo: estima-se que uma pessoa dispense 116 minutos do seu dia acessando as redes sociais YouTube, Facebook, Snapchat, Instagram e Twitter (Mediakix, 2017). A própria página inicial da maior rede social da atualidade, o Facebook (Alexa, 2017; Moz, 2017) ${ }^{1}$, hoje com mais de 2.01 bilhões de acessos mensais ativos e 1.32 bilhões diário ${ }^{2}$ (Facebook, 2017f), indica sua missão: "dar às pessoas o poder de construir comunidades e aproximar 0 mundo. As pessoas usam o Facebook para ficarem conectadas com amigos e família, descobrir o que está acontecendo no mundo e compartilhar e expressar o que importa para elas"3. 


\section{O FACEBOOK COMO DETENTOR E ORGANIZADOR DA OPINIÃO PÚBLICA}

A partir do exposto, pode-se inferir que o processo de cognição do mundo é afetado pelos novos meios digitais, uma vez que a troca de informações participa da formação de conceitos que consideram novas culturas e pontos de vista.

Segundo a empresa Facebook, "um de cada cinco minutos gastos pelos americanos em dispositivos móveis se passa no Facebook ou no Instagram" (Facebook, 2017e) e o número de páginas acessadas que receberam a interação "Gosto" nessa rede aumentou em 50\% em apenas um ano, entre 2013 e 2014 (Facebook, 2017b). Dada essa importância, é pertinente refletir acerca da relevância da troca de informação nessa plataforma virtual.

Sobre esse site, é certo que, ainda que possa ser veículo que oportuniza o alcance a outros espaços e culturas, as informações não são acessadas livremente e ao acaso, mas controladas, pois a escolha daquilo que é apresentado a cada usuário passa por uma triagem da própria empresa: baseados nas características de acesso, demográficas e psicológicas de cada usuário, algoritmos ${ }^{5}$ criados para a organização das informações disponíveis antepõem determinadas informações e omitem outras para cada perfil inscrito. Eles determinam a ordem de postagens do feed de noticias ${ }^{6}$ de cada usuário. Segundo a própria empresa (Facebook, 2017b ${ }^{7}$, em média uma pessoa teria acesso a uma quantidade entre 1,500 e 15,000 postagens por acesso no seu feed de notícias se não houvesse a triagem realizada pelos algoritmos, mas

Em vez de mostrar tudo o que é publicado, o Feed de notícias é desenhado para mostrar o conteúdo mais relevante para cada pessoa. Das 1,500 histórias que podem ser vistas a cada acesso ao Facebook, o Feed de notícias mostra aproximadamente 300. Para escolher quais histórias aparecerão, o Feed de notícias as classifica (da mais relevante para a menos relevante) levando em conta diversos fatores relativos a cada pessoa.

\section{$(\ldots)$}

Como resultado dessas mudanças, o Feed de notícias se tornou mais envolvente para as pessoas, mesmo que a quantidade de conteúdo publicado tenha aumentado. (Facebook, 2017b)

É explícito então que há uma ordem de relevância que não nos é decidida pelos usuários. A pergunta "Por que não mostrar tudo - cada conteúdo produzido por amigos e Páginas - e deixar as pessoas decidirem o que querem ver?" (Facebook, 2017b) é respondida pela própria empresa: para que as histórias mais recentes não tomem o lugar daquelas "mais relevantes". 
Em nossos testes, nós sempre percebemos que o sistema de classificação do Feed de notícias oferece uma experiência melhor no Facebook. Além disso, com a grande quantidade de conteúdo no Feed de notícias, um sistema de entrega em tempo real provocaria uma queda ainda maior do alcance orgânico das Páginas". (Facebook, 2017b).

O alcance orgânico é o número de acessos a uma publicação não paga por usuários individuais para quem uma publicação foi disponibilizada, diferente do alcance pago, que é a quantidade de acessos para quem foi mostrada a publicação de um anúncio publicitário (Facebook, 2017a). A empresa Facebook sugere àqueles que pretendem ter maior alcance entre os usuários que adiram aos anúncios pagos, assim atingem "mais pessoas e com muito mais precisão do que o conteúdo orgânico" (Facebook, 2017b), o que implica dizer que os anúncios pagos têm algumas vantagens no feed.

O Facebook também coloca que tem trabalhado em ferramentas para incrementar 0 envolvimento dos usuários com as marcas pagantes. Uma delas é a utilização de cookies (arquivos que recolhem informações a respeito do usuário). Numa próxima visita ao site que instalou o cookie na máquina do usuário, o arquivo é acessado e são reconhecidas as preferências do visitante. Um cookie pode reter qualquer tipo de informação de navegação e, inclusive, ser alimentado e compartilhado por diferentes websites.

Os cookies são instalados sempre que houver acesso tanto à rede social quanto a empresas do grupo Facebook ${ }^{8}$, a outros websites que usam seus serviços (como os botões "Gosto" ou "Compartilhe" em websites, serviços de anúncio ou mesmo a possibilidade de acessar uma conta com usuário e senha do Facebook) e a empresas que usam os domínios atdmt.com, liverail.com e Instagram.com, e os dados são compartilhados entre os endereços eletrônicos. Neles são armazenados, além de idioma e informações fornecidas pelo usuário em seu perfil: hábitos de compra e anúncios clicados, todas as informações com relação a tráfego, interação, conteúdo de mensagens públicas e privadas, locais de onde o site foi acessado e a cidade atual, dados de reconhecimento facial de si e dos contatos, uma lista de endereços IP dos quais a conta foi acessada, aquilo que se publicou e também o que se ocultou no feed de notícias, solicitações de amizade enviadas, aceitas e pendentes, visões políticas e religiosas e todo o tipo de publicação feita, compartilhada com outras pessoas ou delas consigo $^{9}$, o tamanho, o contraste e a resolução da tela da máquina por onde são acessados o Facebook e os demais sites citados.

Segundo a própria política de cookies do Facebook (Facebook, 2017c), a utilização dessas informações serve para auxiliar na identificação, assim como para mostrar os recursos e experiências que considera apropriados de acordo com as preferências de 
cada usuário, para personalizar conteúdos e anúncios, medir o desempenho de campanhas publicitárias e perceber a interação com anúncios e o perfil dos usuários que interagem com determinadas páginas.

Além dos cookies coletados por sites da "família de empresas do Facebook", também são coletados dados para a exibição de "anúncios baseados em interesse online" (Facebook, 2017c). Não só compartilhados pelos websites em que foram coletados, os dados também podem ser utilizados por empresas que tenham aplicativos e por sites que não pertençam ao grupo Facebook mediante contratação e acordo de aquisição de informações sobre usuários. É possível alterar as preferências de visualização de anúncios, mas, mesmo que se escolha não ver determinado tipo de publicidade, os cookies são depositados no navegador do usuário, que estará na lista de informações disponibilizada a anunciantes.

A empresa possui ainda outras ferramentas para fomentar a penetração de postagens publicitárias. Após pesquisas (Facebook, 2017c), o Facebook admite que as informações de cookies não são tão eficazes para uma divulgação em postagem quanto os dados demográficos que oferece. A empresa, portanto, coleta informações a respeito de seus usuários e as fornece a anunciantes, que então direcionam sua publicidade para seu público-alvo, podendo-se escolher uma ou mais classificações, incluindo: idade, língua, local onde se encontra ou onde mora, interação com produtos e serviços similares ao que se deseja anunciar, dispositivo que mais utiliza para acessar redes sociais e a rede social mais acessada.

Com os dados e ferramentas baseados em pessoas, os profissionais de marketing podem vincular ações diretamente a pessoas reais onde quer que elas estejam, e podem preencher as lacunas de medição existentes em medições tradicionais baseadas em cookies, que não capturam a jornada completa do consumidor" (Facebook, 2017d).

Uma das ferramentas utilizadas para o direcionamento de publicidade é a Publicação de Página não Publicada, ou o que o mercado convencionou chamar de "dark posts". São anúncios direcionados a públicos específicos que não aparecem no feed de notícias do anunciante. Isso significa que podem ser criados diferentes tipos de anúncios, com mensagens diversas e até contraditórias, mas os consumidores, ao entrarem na página do anunciante, não terão acesso ao que foi enviado aos demais públicos-alvo, evitando que reajam negativamente frente a peças publicitárias com mensagens que não os agradam.

Os dark posts foram amplamente utilizados nas eleições presidenciais dos Estados Unidos, como mostrado em Washington Post ${ }^{10}$, Independent ${ }^{11}, C N N^{12}$, The Intercept ${ }^{13}$, The New York Times ${ }^{14}$, The Guardian ${ }^{15}$ e $C N B C^{16}$, quando notícias falsas e verdadeiras, 
memes e vídeos com propaganda no Facebook foram direcionados a diferentes tipos de público, de acordo com suas preferências e baseadas em informações disponibilizadas pela mídia social para a montagem das campanhas de candidatos ${ }^{17}$.

Alexander Nix, CEO (Chief Executive Officer) da empresa Cambridge Analytica, que "usa dados para mudar o comportamento da audiência" (Cambridge Analytica, 2017), explicou, em palestra para o Concordia Summit 2016, como funcionam os "psicográficos" que a empresa utilizou para direcionar mensagens com conteúdo persuasivo a usuários com diferentes perfis psicológicos. Para ele, segmentar a audiência de acordo com dados geográficos e demográficos não faz sentido:

Claramente, dados demográficos, geográficos e econômicos influenciam sua visão de mundo, mas, igualmente importantes, ou provavelmente mais importantes, são os psicográficos. Isto é, uma compreensão de sua personalidade, porque é a personalidade que conduz o comportamento e o comportamento que, obviamente, influencia a forma como você vota. (Concordia, 2016, trecho 2:40 - 3:00)

Ainda segundo o executivo, "hoje a comunicação está cada vez mais direcionada. Está sendo individualizada para cada uma das pessoas desta sala" (Concordia, 2016, trecho $8: 35-8: 46)$.

Para a montagem do perfil dos usuários de redes sociais que receberam determinado conteúdo foram consideradas sua abertura para novas experiências, se prefere ordem, hábitos e planejamento, quão social é a pessoa, se ela coloca as necessidades dos outros, da comunidade, da sociedade à frente dos seus e o quanto esse usuário tende a se preocupar com as questões que lhe atingem. Esse mapeamento se dá pelo cruzamento de informações como as que o Facebook fornece ${ }^{18}$, que vão além de dados geográficos e demográficos, pois, como vimos: "pessoas deixam pegadas em todo lugar sobre seu humor, comportamento, personalidade e experiências" (Kern, et al., 2016, p. 16). Após pesquisa com centenas de milhares de americanos, A Cambridge Analytica montou um modelo que pode compreender "a personalidade de cada adulto nos Estados Unidos da América" (Concordia, 2016, trecho 3:49 - 3:53). Uma vez de posse desses perfis, é possível produzir peças com mensagem mais agressiva ou mais afetuosa, mais racional ou mais emotiva, por exemplo.

Hoje não precisamos adivinhar qual solução criativa pode ou não funcionar. Podemos usar centenas ou milhares de pontos de dados individuais de nossos públicos-alvo para entender exatamente quais mensagens serão apelativas para quais públicos muito antes do início do processo criativo. (Concordia, 2016, trecho $5: 14-5: 35)$ 
A seleção de público-alvo, portanto, pode incluir dados demográficos e geográficos ou dados psicográficos, "isso é: hábitos de consumo e estilo de vida, quais produtos você compra em lojas, quais as revistas que lê, a qual clube de golfe pertence, a quais igrejas vai e, claro, (...) como você vê o mundo, o que o impulsiona" (Concordia, 2016, trecho $6: 02-6: 22)$.

Pesquisa da APA (American Psychological Association) corrobora a tese de que os dados de usuários podem levar a conhecer como pequenos grupos percebem o mundo fora da virtualidade a partir da linguagem utilizada em mensagens online (Kern, et al., 2016):

Por meio de plataformas como Facebook e Twitter, e-mails, mensagens de texto e fóruns, as pessoas compartilham uma quantidade considerável de informações linguísticas. Uma quantidade crescente de dados também está disponível sob a forma de comportamentos explícitos (por exemplo, "gosto", respostas de pesquisa, páginas pesquisadas), comportamentos monitorados de maneira discreta (por exemplo, passos por dia, localização, tempo gasto online) e imagens. (Kern, et al., 2016, p. 2)

Segundo a pesquisa, a linguagem utilizada em mídias sociais, captada por pesquisas de big data ${ }^{19}$, já oferece insights sobre a personalidade e características individuais a um nível refinado, possibilitando compreender como os usuários percebem o mundo. Pelo estudo da linguagem utilizada nesse ambiente online pode-se chegar a identificar contextos a nível de redondezas pequenas (Kern, et al., 2016), não somente de um país ou cidade, por exemplo.

\section{A QUESTÃO DA LIBERDADE DIANTE DA MANIPULAÇÃO DO DISCURSO}

Diante do conhecimento de que websites como o Facebook têm poderosos bancos de dados, pois detêm informação que pode servir para a produção de discursos psicologicamente envolventes, questiona-se a possibilidade de liberdade. Isso porque, uma vez que a opinião pública pode ser moldada a partir de dados fornecidos pela navegação online, qual é a possibilidade de estarmos livres quando usamos a internet? Se antes as mídias sociais poderiam ser vistas como espaço de troca sem limites geográficos, lugar de expansão e construção e de alargamento de conhecimento do mundo por meio de encontros com o diverso, agora já se pode pensá-las como produtos de empresas privadas que, por visarem à obtenção de rendimentos, monetizam informações sobre seus usuários. Se essas informações são utilizadas para convencêlos de determinadas escolhas por discursos moldados segundo seu perfil psicológico, como fica então a possibilidade de escolha por meio de racionalização e ponderação? 
Morin e Merleau-Ponty defendem que o conhecimento do objeto é dependente do sujeito e este, por sua vez, não é desvinculado do contexto em que está, da história que o precede nem da sua biologia, de forma que o objeto como o conhecemos também só pode estar atrelado a esses fatores. Para o primeiro, não nos tornamos autônomos (livres, donos de nossa própria opinião) antes de aprendermos uma linguagem, uma cultura, saberes, que devem ser variados para que possamos exercer a escolha daquilo que seremos, de forma que a autonomia se alimenta da dependência desses fatores. Também a biologia, nossos genes, ditam como vivemos e, portanto, somos também dependentes deles (Morin, 2011). Para Merleau-Ponty (1999), somente podemos sentir após aprendermos - com a história, as tradições, a vivência do corpo, as informações adquiridas - o que é cada uma das sensações. A percepção só é classificada após a aquisição de conceitos, que nos são dados e dependemos deles para podermos construir o mundo. Assim, só podemos optar diante daquilo que temos. Não há escolha que não tenha motivações:

A escolha que fazemos de nossa vida sempre tem lugar sobre a base de um certo dado. Minha liberdade pode desviar minha vida de sua direção espontânea, mas por uma série de deslizamentos, primeiramente esposando-a, e não por alguma criação absoluta. Todas as explicações de minha conduta por meu passado, meu temperamento, meu ambiente são portanto verdadeiras, sob a condição de que os consideremos não como contribuições separáveis, mas como momentos de meu ser total do qual é-me permitido explicar o sentido em diferentes direções, sem que alguma vez se possa dizer se sou eu quem lhes dá seu sentido ou se o recebo deles. Sou uma estrutura psicológica e histórica. Com a existência recebi uma maneira de existir, um estilo. Todos os meus pensamentos e minhas ações estão em relação com esta estrutura (...) E todavia sou livre, não a despeito ou aquém dessas motivações, mas por seu meio. (Merleau-Ponty, 1999, pp. 610-611)

Merleau-Ponty (1999) reconhece a liberdade como a possibilidade de transformação sempre a partir da escolha amparada pelo dado, pelas influências. Mesmo diante de informações falsas ou limitadas somos livres. A liberdade está na decisão moral, na opção por conservação ou criação, porque, se "o próprio do percebido é admitir a ambigüidade, o 'movido', é deixar-se modelar por seu contexto" (Merleau-Ponty, 1999, p. 33), há flexibilidade. Como aponta o pensador, não há criação absoluta, mas o sentido pode ser explicado de diferentes maneiras, e é o sujeito que escolhe uma delas.

Morin (1977) considera a liberdade "o bem supremo" (p. 33) e a define como a "possibilidade de decisão e escolha" (p. 74), de como pensar e agir mediante a reflexão baseada no encontro com a pluralidade de formas de ver o mundo (idem). Por isso está ligada à admissão de uma sociedade complexa, ou seja, à aceitação de que uma sociedade, enquanto sistema complexo, traz em si uma multiplicidade de pensamentos, 
inclusive divergentes, que precisam ser considerados quando da construção do conhecimento: "Uma sociedade muito complexa proporciona muitas liberdades de jogo a seus indivíduos e grupos" (p. 19). Destarte, a complexidade se funda na liberdade dos indivíduos constituintes do sistema (idem). O indeterminismo e o acaso, elementos relacionados à desordem, que é provocadora de encontros e de rupturas, possibilitadora de flutuações, que alimenta "a constituição e o desenvolvimento dos fenómenos organizados" (p. 75), estão relacionados com a liberdade. É da desordem que brotam as emergências, que se abrem novas possibilidades de conhecer o mundo dos fenômenos, ou seja, o mundo que é acessível a nós. As emergências não são base inalterável, fundamento ontológico, mas "frutos últimos", assim como "a consciência, a liberdade, a verdade, o amor, são frutos, flores (...). Representam aquilo que há de mais frágil, de mais alterável: um nada os desflora, a degradação e a morte surpreende-os, e nós julgamo-los ou queremo-los imortais" (p. 108).

É por isso que a liberdade precisa adotar o inesperado e não admite um mundo no qual não se pode escapar do que é dado. A ação deve ter em conta a complexidade, e isso implica em aceitar "o aleatório, acaso, iniciativa, decisão, inesperado, imprevisto, consciência de derivas e transformações" (Morin, 2000, p. 87). A liberdade está para a estratégia, não para o programa (idem), isto é, para a elaboração de um cenário de ação que considera as certezas e incertezas das situações para pensar em probabilidades e improbabilidades. Ao contrário do programa, que não aceita modificações das condições externas, a estratégia admite alterações no cenário a partir da consideração dos acasos, contratempos ou oportunidades que vão se fazendo. Se a liberdade é a possibilidade de escolha, então é na estratégia, e não na programação, que a ação livre se encontra.

Morin trata da autonomia dos indivíduos como uma liberdade frente ao autoritarismo e ao despotismo. Os autônomos que se rebelam contra a opressão são desvios em um sistema que possui regulações e repressões, e aniquilar as diferenças que emergem é, para os autoritários, aniquilar o desvio, mas "toda evolução é fruto do desvio bemsucedido cujo desenvolvimento transforma o sistema onde nasceu: desorganiza o sistema, reorganizando-o" (Morin, 2000, p. 82). Por isso há de se esperar o inesperado, ainda que, porque é inesperado, ele nos surpreenda. É necessário acolher o novo, ainda que seja de sua natureza brotar sem parar.

Não podemos jamais prever como se apresentará, mas deve-se esperar sua chegada, ou seja, esperar o inesperado (...). E quando o inesperado se manifesta, é preciso ser capaz de rever nossas teorias e idéias, em vez de deixar o fato novo entrar à força na teoria incapaz de recebê-lo" (Morin, 2000, p. 30)

Se então a liberdade implica a complexidade, se indica a visão do mundo como um sistema repleto de sistemas distintos, pode-se dizer que o Facebook é cenário para as 
manifestações de liberdade, já que as informações podem ser de imensa variação, a respeito de realidades que não alcançaríamos se não por meio do intercâmbio informacional que essa rede social nos poderia proporcionar, permitindo o encontro com o desconhecido e o aleatório e a tomada de decisão a partir da ponderação do que se vem a conhecer. Paradoxalmente, a ação livre requer autonomia de pensamento diante do que é dado e deve ser estratégica no sentido de admitir o inesperado, o que vai de encontro à seleção de informações por algoritmos altamente especializados em oferecer ao indivíduo aquilo que Ihe agrada. Isso significaria uma castração da liberdade, a manobra para a homogeneização da opinião, para a simplificação e esquiva da complexidade.

As imposições que inibem enzimas, genes, e até células, não diminuem uma liberdade inexistente a este nível, pois a liberdade só emerge a um nível de complexidade individual onde há possibilidades de escolha; inibem qualidades, possibilidades de acção ou de expressão. É só ao nível de indivíduos que dispõem de possibilidades de escolha, de decisão e de desenvolvimento complexo que as imposições podem ser destrutivas de liberdade, isto é, tornar-se opressivas. Assim, este problema das imposições surge de modo simultaneamente ambivalente e trágico ao nível das sociedades, e singularmente das sociedades humanas. (Morin, 1977, p. 11. Grifos do autor)

A ideia de liberdade que temos ao acessar o Facebook porque acreditamos na expansão do nosso conhecimento de mundo, na aquisição de novas informações para a escolha livre, é, portanto, falsa.

\section{CONSIDERAÇÕES FINAIS}

Vê-se que o Facebook pode ser um espaço de troca de informação que termina por ser campo onde se desenvolve conhecimento. Nesse sentido, pode enriquecer e tornar mais complexo o mundo criado. No entanto, sendo que as informações que cada usuário recebe é controlada por algoritmos e anunciantes, o mundo criado é parcialmente delimitado por eles. Se os limites do conhecimento, ou seja, da história, da cultura, do saber, são os limites da percepção e esta, por sua vez, é a baliza da criação do mundo, então o que acabamos por receber da interação no Facebook por muitas vezes são fronteiras, não aberturas.

O Facebook elide diversos pontos que fabricam o mundo como sistema complexo e o simplifica, ou seja, pela curadoria de informações baseadas nas características do usuário, reforça apenas suas preferências e o ponto de vista que já lhe pertence, mostraIhe um mundo homogêneo. Merleau-Ponty defende que há liberdade mesmo em ambientes planejados, sendo que a ação livre é a própria decisão diante dos fenômenos e a partir do que é conhecido, admitindo a flexibilidade, mas o encontro com o 
pensamento da complexidade leva-nos a pensar a ideia merleau-pontyana: tal manipulação das informações nos priva de um pano de fundo para nossas ações e escolhas de infinitas possibilidades, limita o mundo, que é substrato da nossa espontaneidade, da capacidade de criação, ou seja, controla o campo fenomenal e assim limita as possibilidades por sobre as quais flutua nossa liberdade.

Ainda que a liberdade, para Merleau-Ponty, não possa existir sem a limitação de um campo, se temos conhecimento da complexidade dos sistemas em que estamos inseridos, podemos escolher por viver em um mundo onde as informações são restritas e as opiniões são fomentadas (e muitas vezes manipuladas) ou em um mundo no qual se admite a multiplicidade de pensamentos; podemos escolher o confronto e a racionalização, a ponderação, mesmo que isso signifique uma ponderação que não pode deixar para trás as influências da história, do contexto, da cultura. Se a liberdade é a própria escolha, a noção da complexidade e das limitações impostas pelos algoritmos é o que nos levará a escolher entre os múltiplos sentidos dos objetos e do mundo. No mundo complexo, a liberdade alarga suas fronteiras de forma que o contexto que a influencia possui ainda mais elementos de culturas diversas, o campo torna-se uma região mais alargada geograficamente, o tempo não é só o dos que nos estão próximos, mas é também o passado daqueles que estão, inclusive, em localidades distantes de nós. "O mundo está já constituído, mas também não está nunca completamente constituído" (Merleau-Ponty, 1999, p. 608). Com isso quer dizer que a liberdade está limitada àquilo que se pode reter do mundo considerando-se que já há algum sentido que lhe foi dado antes de nascermos, mas também que há sempre a possibilidade de constituição para cada um. Além disso, "uma consciência para quem o mundo é 'óbvio', que o encontra 'já constituído' e presente até nela mesma, não escolhe absolutamente nem seu ser, nem sua maneira de ser" (p. 608, grifo do autor).

Diante do conhecimento da complexidade, podemos escolher não a simplicidade oferecida por empresas que evitam confrontos de opiniões e histórias, mas vivermos num sistema complexo, escolher a escolha, optar por conhecer o desconhecido, o oposto, que leva à reflexão, podemos ao menos tentar desviar das barreiras algorítmicas uma vez cientes da manipulação da informação disponibilizada.

\section{Notas}

${ }^{1}$ Segundo as fontes citadas, o Facebook.com é o terceiro site mais acessado do mundo e é o maior em número de sites que se remetem a ele.

2 Dados disponíveis em https://newsroom.fb.com/company-info/. Pelas pesquisas de http://www.internetworldstats.com/stats4.htm (baseadas em dados oferecidos por sites considerados confiáveis (ver lista no endereço), nos 53 países europeus, em junho de 2017, havia $343,373,740$ usuários do Facebook, o que representa $52 \%$ da população online da Europa, 
onde a penetração da internet é de $82 \%$ da sua população. Em Portugal, $72 \%$ da população possui acesso à internet, dos quais $56.5 \%$ possuem contas no Facebook (Internet World Stats, 2017).

${ }^{3}$ Disponível em: https://newsroom.fb.com/company-info/.

${ }^{4} \mathrm{O}$ Instagram também é uma rede social digital da empresa Facebook.

${ }^{5}$ Algoritmos são sequências lógicas pré-estabelecidas, finitas e definidas de instruções em linguagem computacional que orientam máquinas e websites a estipular como executar uma tarefa ou resolver um problema.

${ }^{6}$ Página onde são disponibilizadas postagens de amigos, empresas e publicidade.

${ }^{7}$ Informação disponível em https://www.facebook.com/notes/socialbakers/3-important-updatesto-facebook-algorithm-in-january-2017/10155032524044744/

${ }^{8}$ São empresas do Facebook: Facebook Payments Inc.; Atlas; Instagram LLC; Onavo; Moves; Oculus; WhatsApp Inc.; Masquerade e CrowdTangle. Cada uma tem termos de uso e privacidade próprios. Informação disponível em: https://www.facebook.com/help/111814505650678.

${ }^{9}$ Uma tabela com a listagem de todas as informações coletadas que podem ser disponibilizadas, mediante solicitação por parte do usuário, está disponível em: https://www.facebook.com/help/405183566203254?helpref=faq_content. A página "Que categorias dos meus dados do Facebook estão disponíveis para eu consultar?" não esclarece se outras informações são coletadas e armazenadas, apenas lista aquelas que estão disponíveis para download pelo usuário.

${ }^{10}$ Ver: "Trump campaign's embrace of Facebook shows company's growing reach in elections", de Matea Gold e Elizabeth Dawson, a 8 de outubro de 2017, em: https://www.washingtonpost.com/politics/trump-campaigns-embrace-of-facebook-showscompanys-growing-reach-in-elections/2017/10/08/e5e5f156-a93b-11e7-b3aac0e2e1d41e38_story.html. Acesso em 24 de janeiro de 2019.

${ }^{11}$ Ver "Facebook must wake up to its disastrous potential - it has the power to subvert American democracy", de James Moore, a 21 de outubro de 2017, em: http://www.independent.co.uk/voices/facebook-american-democracy-russia-mark-zuckerbergsheryl-sandberg-a8012516.html. Acesso em 24 de janeiro de 2019.

${ }^{12}$ Ver: "Donald Trump's mind readers try to win him voters", de Isa Soares, a 4 de novembro de 2016, em: http://edition.cnn.com/2016/11/04/politics/donald-trump-political-ads-cambridgeanalytica/index.html. Acesso em 24 de janeiro de 2019. 
${ }^{13}$ Ver: "Facebook failed to protect 30 million users from having their data harvested by Trump campaign affiliate", de Mattathias Schwartz, a 30 de março de 2017, em: https://theintercept.com/2017/03/30/facebook-failed-to-protect-30-million-users-from-havingtheir-data-harvested-by-trump-campaign-affiliate/. Acesso em 24 de janeiro de 2019.

${ }^{14}$ Ver: "Data firms says 'secret sauce' aided Trump; many scoff", de Nicholas Confessore e Danny Hakim, a 6 de março de 2017, em: https://www.nytimes.com/2017/03/06/us/politics/cambridgeanalytica.html?smid=fb-nytimes\&smtyp=cur. Acesso em 24 de janeiro de 2019.

${ }^{15}$ Ver: "Cambridge Analytica used data from Facebook and Politico to help Trump", de Stephanie Kirchgaessner, em 26 de outubro de 2017, em: https://www.theguardian.com/technology/2017/oct/26/cambridge-analytica-used-data-fromfacebook-and-politico-to-help-trump. Acesso em 24 de janeiro de 2019.

${ }^{16}$ Ver: "The man who helped Trump use Facebook to get elected says algorithms can bring out our 'worst"', de John Shinal, a 15 de setembro de 2017, em: https://www.cnbc.com/2017/09/15/cambridge-analytica-darren-bolding-says-donald-trumpfacebook.html. Acesso em 24 de janeiro de 2019.

17 V.f.: Anderson, 2017: The Rise of the Weaponized Al Propaganda Machine, em https://scout.ai/story/the-rise-of-the-weaponized-ai-propaganda-machine. Acesso em 24 de janeiro de 2019.

${ }^{18}$ Alexander Nix, na palestra citada, revela que dados do consumo de programas de televisão também são coletados de operadoras de TV digital (Concordia, 2016).

${ }^{19}$ Big Data é um conjunto muito grande e complexo de dados de muitos indivíduos que são capturados e armazenados e podem fornecer informações para análises, pesquisas e questões de privacidade.

\section{Referências}

Alexa. (16 de outubro de 2017). Alexa, an A17, disponível em https://www.youtube.com/watch?v=n8Dd5aVXLCc

Facebook. (27 de outubro de 2017a). Centro de ajuda. Fonte: Facebook: https://www.facebook.com/help/285625061456389?helpref=uf_permalink

Facebook. (23 de outubro de 2017b). Alcance orgânico no Facebook: suas dúvidas respondidas. Fonte: Facebook: https://www.facebook.com/business/news/BR-Alcance-organico-noFacebook-suas-duvidas-respondidas

Facebook. (23 de outubro de 2017c). Cookies e outras tecnologias de armazenamento. Fonte: https://www.facebook.com/policies/cookies/ 
Facebook. (25 de Outubro de 2017d). Marketing baseado em pessoas: planejamento e medição priorizando as pessoas. Fonte: Facebook IQ: https://www.facebook.com/iq/articles/thefuture-of-marketing-people-based-planning-and-measurement

Facebook. (23 de outubro de 2017e). Facebook para empresas. Fonte: Site do Facebook: https://www.facebook.com/business/products/ads

Facebook. (15 de outubro de 2017f). Facebook Newsroom. Fonte: https://newsroom.fb.com/company-info/

Fang, I. (1997). AHistory of mass communication: six information revolutions. Oxford, United Kingdom: Butterworth-Heinemann.

Kern, M. L., Park, G., Eichstaedt, J. C., Schwartz, H. A., Sap, M., Smith, L. K., \& Ungar, L. H. (8 de agosto de 2016). Gaining Insights From Social Media Language:. Psychological Methods, pp. 1-19. doi:10.1037/met0000091

Leiner, B. M., Kahn, R. E., Postel, J., Cerf, V. G., Kleinrock, L., Roberts, L. G., \& Wolff, S. (outubro de 2009). A brief History of the Internet. ACM SIGCOMM Computer Communication Review, pp. 22-31.

McLuhan, M. (1969). Os meios de comunicação como extensões do homem. São Paulo: Cultrix.

Mediakix. (16 de outubro de 2017). Mediakix. Fonte: How much time is spent on social media?: http://mediakix.com/2016/12/how-much-time-is-spent-on-social-media-lifetime/

Merleau-Ponty, M. (1999). Fenomenologia da Percepção (2a ed.). São Paulo: Martins Fontes.

Morin, E. (1977). O método: 1. a natureza da natureza (2 ed.). Portugal: Europa - América.

Morin, E. (2000). Os sete saberes necessários à educação do futuro (2 ed.). Brasília: UNESCO.

Morin, E. (2011). Introdução ao pensamento complexo (4ª ed.). Porto Alegre: Sulina.

Moz. (18 de outubro de 2017). Moz. Fonte: Moz: https://moz.com/top500

Nóbrega, T. P. (2008). Corpo, percepção e conhecimento em Merleau-Ponty. Estudos de Psicologia, pp. 141-148. 